\title{
On understanding people, structure, desires, and ourselves
}

Felipe Morales-Carbonell (ef.em.carbonell@gmail.com) Facultad de Filosofía y Humanidades, Universidad de Chile (Santiago, Chile) https://orcid.org/0000-0001-5492-0759

\begin{abstract}
Stephen Grimm defends the idea that for understanding people, we need to think of understanding not only in terms of grasp of structure (be that causal or of other kinds) but also in terms of a notion of understanding-as-taking-to-be-good. In this paper, I critically examine this idea. First, I argue that in some cases, understanding-as-taking-to-be-good can be explained in terms of understanding-asgrasp-of-structure. Then, I consider one further way in which understanding-as-taking-to-be-good could be obtained through something which is not a form of grasp of structure, which narrows and refines Grimm's understanding-as-taking-to-be-good concept.
\end{abstract}

Key words: understanding of people, grasp of structure, desirability, imagination.

\section{Introduction}

It is somewhat of a commonplace that the social sciences aim to understanding the human world. By which means this understanding should be achieved is a matter of much dispute, constituting a traversal issue in the philosophy of the social sciences. Preliminarily, however, we should also address the question of what kinds of understanding should be a concern for the social sciences, that is, what we may mean by 'understanding' in this context.

Recent work in the epistemology of understanding has identified a great diversity in what one could (or should) mean by 'understanding' across contexts, and there is no shortage of theories of understanding (Grimm Understanding). It is necessary to take stock, then, of the available alternatives.

It is important to note that the epistemology of understanding as a contemporary subdiscipline emerged from the intersection of work by people in mainstream epistemology, who were and are worried about epistemic value, and in the philosophy of science, whose main concern was explanation. This had the result that models of understanding have been developed mainly in view of its role in the natural sciences. However, more recent work has looked into the role and varieties of understanding in the social sciences as well, and in particular, on how understanding people might differ from understanding other subject matters (Cooper Understanding people; Stueber Understanding versus explanation, The ubiquity of understanding; Grimm How understanding people differs from understanding the natural world, Why study history).

Here, I want to focus on the contributions of Stephen Grimm to the discussion of understanding in the social sciences, and in particular on the notion of understanding-as-taking-to-be-good (that he develops in How understanding people differs from understanding the natural world). Grimm's 
perspective is significant, as I hope to make clear here, because it aims to recover the value of understanding in the social sciences within the context of a naturalist-friendly picture, without capitulating to the reductionist temptations that sometimes can be perceived in such attempts. However, I think that the position needs to be examined critically, with some points of the account requiring a closer look. That will be my goal here. I will proceed as follows. First, I will briefly summarize Grimm's position, and explain his distinction between understanding-as-grasp-ofstructure (UGS) and understanding-as-taking-as-good (UTG). Grimm argues that the latter can't be reduced to the former. Against this, I will push the concern that in many of the cases where Grimm identifies understanding-as-taking-as-good as irreducible to understanding-as-grasping-of-structure the reduction can in fact be done, as long as we make use of suitable notions of structure and in particular of desirability (notions that, plausibly, Grimm would also endorse). Finally, I will examine if there may still be some way in which understanding people could go beyond 'grasp of structure', and I will suggest that by making ourselves desire what rationalizes the action of others (the object of their desires), we could have a different way to understand them. So, while there is a way in which we can understand people in a way that can't be accounted for in terms of grasp of structure, the scope of this form of understanding is more restricted than Grimm argues.

\section{Grimm on understanding in the social sciences}

As is well known, one of the central questions in the philosophy of the social sciences is whether the goals of the social sciences should be pursued by the same means or means like those that the natural sciences use to pursue their goals. Against both those who would like to draw a strict boundary between the social and natural sciences, asserting the independence of the interpretative methods of the social sciences, and those who would absorb the social sciences into the natural sciences, Grimm's goal is to show how the social sciences have goals which are both alike and independent from the natural sciences.

On the one hand, the social sciences will, like the natural sciences, be concerned with the structure of specific objects in its domain, the domain of social phenomena; that is, the social sciences are at least partially concerned with questions about how social phenomena are constituted, the causal mechanisms that underlie them, and so on. On the other hand, the social sciences also concern themselves with the intelligibility of the actions of people; that is, they aim to make comprehensible the reasons for which people act as they do. While some authors like Dilthey would describe this two-pronged structure of the social sciences in terms of a distinction between explanation and understanding, the former representing the grasp of structure that is akin to social and natural sciences, and the latter representing the grasp of people that is unique to the social sciences, Grimm suggests that we should think of both sides of the matter in terms of different types of understanding. Instead of different goals (explanation vs. understanding), what we will have is one goal (understanding) that takes a variety of shapes. Like Stueber (Understanding versus explanation), Grimm thus argues that we cannot find the distinction between the social and natural sciences on any supposed distinction between the nature of their respective aims, since the nature of those aims at least partially overlaps.

It should be made clear that this does not mean that we should take understanding as the only aim of the social sciences. The point is rather that we should see (some of) the kinds of goals that are sometimes put under the umbrella term of 'explanation' as forming part of the goal of understanding. In fact, Grimm defends the view that causal knowledge provides a distinct form of 
understanding. However, Grimm argues that this form of understanding is an instance of a more general kind, understanding-as-grasping-of-structure (UGS), which he characterizes as follows: "this is the sort of understanding one achieves when one apprehends how the various elements of a system depend upon one another, so that one can potentially manipulate the system in various ways -or, at least, so that one can predict or 'see' how changing some elements of the system will lead, or fail to lead, to changes in the other elements" (Grimm 2016:214).

An ordinary case of UGS is understanding a machine or tool. We see that it has different parts that interact with one another, and with things that it acts on when used (how, for example, a pair of scissors cut paper by moving in certain ways). We understand how it works by grasping its structure. Complex things can be understood in terms of the causal relations between their parts. Grasp of causes is a form of UGS in so far as causal relations are a kind of dependency relation. But there is no need to think that causal relations are the only target of UGS. For example, relations of constitutive dependency or even class inclusion could play a similar role. In this vein, Grimm points out that one could also some obtain some form of UGS just by identifying the factors or variables that may play a role in the behaviour of our targets (for example, when identifying that some not yet specified element could play some specific role in a functional explanation). In Grimm's view, understanding involves some form of control or capacity to manipulate either the target of our understanding or of our representations of the target, a point that has also been emphasized by Hills (Understanding why) and Wilkenfeld (Understanding as representation manipulability).

UGS is an epistemic good for both the natural and social sciences. This can be illustrated by the prevalence of functional and structural explanations in both cases. These sorts of explanations, Grimm argues, provide understanding in terms of grasp of structure.

That we grasp dependencies relation in isolation is not sufficient for us to have a full (or even a rich) understanding of the target phenomena of interest. This is important for the applicability of UGS in the social sciences in two closely related ways. First (and this is a general issue that also affects the natural sciences), not all dependence relations an object of study may be involved in make a difference to its behaviour; some things that are causally related to a phenomenon should be screened off as irrelevant for explanatory purposes (the presence of air for the explanation of the collapse of civilizations, for example). Second, the phenomena that are of interest to the social sciences are typically holistically embedded. We may explain the actions of John by pointing out to the beliefs and desires that are immediately relevant (for example, we could say that he ran away because we believed that there was a risk and wanted to avoid it) and grasping the dependence relations between his actions and specific beliefs and desires provides with understanding. But we may also want to consider how these beliefs and desire cohere with the rest of John's beliefs and desires, and with the beliefs and desires that are characteristic of any groups that John may be a part of. Despite having a psychological/individual explanation of John's actions, we still may think that we don't understand them in view of the bigger picture (for example, imagine that he is a member of a tribe that has peculiar norms about when to flee in the face of danger that his behaviour contradicts). A rich understanding of people in their social context involves grasping the structure of wide networks of things, people, institutions, processes, and so on.

Despite its importance, Grimm points out that understanding-as-grasping-of-structure is not all we may want in the context of the social sciences. When it comes to understanding people, in particular, we may be interested in how acting in a certain way is choiceworthy or desirable for those who we 
want to understand, and further, we may be interested in being able to recognize those things ourselves as choiceworthy or desirable, that is, a "sort of understanding or intelligibility that concerns the goods that are desired in the first place" (Grimm 2016:216). This latter form of understanding is what Grimm calls understanding-as-taking-to-be-good (UTG).

Grimm allows that some instances of understanding how people take things as desirable can be accounted for in terms of the holistic UGS that we just described, but UTG is not the same thing as understanding in the holistic sense we just described. We may understand someone's actions holistically and think that they are coherent and still think that we are missing something (precisely, we may be missing a grasp of how whatever motivates the action could be taken as a good). To have that, we require "a different cognitive attitude -and hence, apparently, a different cognitive method" (Grimm 2016:217). So, acknowledging the possibility of UTG gives us a reason to think that the methodology of the social sciences cannot be reduced to the ways by which we acquire UGS, that is, the ways by which we grasp the structure of the dependence relations involved in social phenomena. Furthermore, Grimm claims, this rationalizes why we may expect the study of the social sciences to acquire a series of intellectual and moral virtues such as tolerance and intellectual humility: to the degree that we are able to grasp how someone else's goals are choiceworthy, we might be less tempted by their correlative intellectual and moral vices. In a different paper (Why study history), Grimm argues, along similar lines, that the study of history may put us in position to acquire the epistemic good of wisdom, which is knowledge of how to live well (Grimm Wisdom).

\section{Revisiting the link between UTG and grasp of structure}

Grimm's account of the varieties of understanding in the social sciences provides a rich framework where, within a broadly naturalistic perspective, some important space is given to methodologies that may not typically be seen as compatible with naturalism. Grimm stops short of attempting a full naturalization of interpretative methodologies because of his rejection of two ideas: first, he rejects that UTG can be reduced into a form of UGS (call this the reduction thesis), and second, he rejects that for the goals of the social sciences, the pursuit of UGS without covering the cases that motivate acknowledging UTG is sufficient (call this the sufficiency thesis). Put in other way, he argues that UTG cases are indispensable for the project of the social sciences (against sufficiency), and he argues that they constitute a distinct type of understanding (against reduction). It must be noted that the indispensability of UTG cases does not, by itself, support the irreducibility thesis: they might be indispensable but reducible to instances of UGS.

With that in mind, while I think that Grimm has done enough to dismiss the sufficiency thesis (although I will return to this point later), I am worried that he has not done enough to dismiss the reduction thesis. It pays off to examine in more detail the structure of Grimm's reasoning here. He proceeds by considering characteristic instances of UGS and asking whether it is possible for someone who has UGS of that type to fail to understand in some sense. Then, when he tries to characterize a sense of understanding that can capture what is missing at the previous stage, he examines if that type of understanding can be accounted for in terms of UGS. If we follow along, we go from causal knowledge to the possession of models in terms of belief/desire pairs, to the placement of those models in the context of networks of beliefs and desires. At the final step, when he considers the question of whether UTG can be reduced to UGS, he relies on the observation that judging that something is potentially worth desiring or desirable does not seem accountable in 
terms of grasp of structure; as we saw above, Grimm thinks that it seems to require 'a different cognitive attitude'.

Is that so? What are the mechanisms that we use to judge or grasp that something is desirable? In this section I will argue that the epistemology of desirability in fact does not require a different attitude, and that in many cases UTG as described by Grimm involves a grasp of structure.

It will pay off to think on the preliminary question of what 'desirability' is intended to mean. One possible starting point is the idea that something is desirable iff it is possible to desire it. To judge that, perhaps we only need to imagine that there is a possibility where someone desires it, a possibility where that is coherent. However, this is surely not what Grimm means by 'desirable', because then grasping how it is coherent to desire something would be sufficient to judge that it is desirable (and this is something that can be accounted purely in terms of UGS, as Grimm observes). The type of possibility involved in this notion is also too general and undiscriminating: perhaps, for anything that can be desirable in this sense, anybody could desire it. So, desirability in this sense could play no role in showing why someone acted in a way rather than any other.

Rather, I take it, Grimm's idea is that something can be judged as desirable in the relevant sense only in so far as one recognizes that one is able to desire it (call this self-centered desirability). Under at least one plausible way to take this idea, understanding (in a sense that requires the ability to judge something as desirable for oneself) requires the ability to know one's own abilities to desire. Two things must be noted. First, that desirability (the property of something to be desired) and the ability to desire (the property of someone who desires) come as an entangled pair, and they are both grounded on the structure of the situation at hand. Desirability is thus plausibly a relational property, between a desirable thing or good, the subjects who can desire it, and their situations (compare with McDaniel \& Bradley Desires, who analyse desires in terms of a relation between a subject, the object of desire, and the condition of desire). The way in which desirability is entangled with abilities to desire makes it viable to explain our knowledge of the former in terms of the latter (at least partially). Second, a lot hinges on how one characterizes oneself as the bearer of the ability to desire, whatever the target of those desires may be. Is the self that matters one's actual self, or is it a version of oneself, that can differ in a range of ways? If one is not careful and takes the relevant self as something that can undergo severe changes, there is a risk to collapse the relevant kind of possibility into the too general type of possibility that we examined above.

Given this self-centered notion of desirability, the question arises of how we can have epistemic access to it, that is, how we can make judgements about it. Given the links I just described between desirability and certain abilities, one strategy could be to sketch how we make judgements of ability in general, accounting for the epistemology of self-centered desirability as a special case. Because the relevant ability is itself self-centered, it will be important to ask whether this makes a difference in the kind of account we can give of knowledge of desirability. If it does, that could account for Grimm's idea that UTG involves a different kind of attitude that goes beyond what is involved in UGS.

There are many ways in which we can recognize or make judgements about the abilities of others without recourse to their own testimony. To illustrate, consider how we would judge that someone found chocolates desirable and thereby ascribe them with the ability to desire chocolates. We could do it by: 
(a) evaluation of their past performances: we see that Sven ate chocolates, we explain that in terms of their past desires to eat chocolates, and we reason that they judged eating chocolates as desirable, an exercise of their ability to desire chocolates,

(b) evaluation of the performance of similar agents in the past: we see that Sven's sister, Sara, ate chocolates, which we explain in terms of their past desires to eat chocolates. We recognize that Sven is in many relevant senses like Sara (for example, that like her he also tends to enjoy eating sweets), and we reason that Sven could judge eating chocolates as desirable, which would also be an exercise of their ability to desire chocolates,

(c) imagining or conceiving of scenarios where agents act considering the relevant desires: we imagine Sven eating chocolates, and we judge that Sven can desire eating chocolates.

Likewise, we can recognize and make judgements about our own abilities in terms of our own past performances, in terms of our similarity to those who have manifested those abilities, and by means of the imagination and our capacities to reason through hypothetical scenarios. So, on an initial approximation, the ways in which we may recognize our abilities to desire need not be any different from the ways in which we may recognize someone else's abilities to desire.

It could be argued that being able to make judgements of desirability based on the first and second mechanisms is not the kind of thing that manifests understanding of how certain things are desirable for someone. In a sense, they push the question back to how we could have ascribed desires in the first place in the cases that we use to base our inductive reasoning on. Considering this, it seems as if the source of justification for our judgements concerning someone's ability to have certain desires must ultimately involve something like (c), where we imaginatively reconstruct and simulate the mental state of those who we want to understand.

Imagining how someone could find something desirable involves a form of grasp of structure. As I pointed out above, desirability is a relational property. Because of this, to grasp it or imagine it, it is not enough to attend to or imagine the object that is evaluated as desirable in isolation. While something could be said in favour of a notion of intrinsic desirability (although I won't attempt to do that here), surely in the context of the social sciences at least, and in our attempts at understanding people more generally, we are interested in how something can be desirable in a given context, precisely because the context in some sense explains that it can be desired. Grimm himself points out that our attempts at understanding people "take place against what we might call a 'background of intelligibility'” (2016: 218).

$E$, a member of culture $A$ in general finds $X$ desirable, whereas $F$, a member of culture $B$, in general would never find it so. What makes the difference? One plausible explanation would look at the differences in $\mathrm{A}$ and $\mathrm{B}$, that is, the contexts where $\mathrm{E}$ and $\mathrm{F}$ act and form their actual beliefs and desires. For another example, go back to the scenario we discussed above: Sven's desires for chocolate can be explained at least partially in terms of the opportunities that the environments he engages with afford them (for starters, because they are the kinds of environments where one can find chocolates), and also by the context of his own personal history (for example, that they have not associated eating chocolate with having stomach aches, something that they want to avoid). Plausibly, to know a context in which some $X$ is involved just is to know the structure of how things are arranged in a situation that involves $X$. In so far as we need to grasp the structure of the situation that we are in and whatever opportunities it affords us and makes salient, this is also crucial for the recognition of our own abilities. 
Given all this, it seems as if, to know someone's abilities to desire, we do not make use of any mechanism that involves a special cognitive attitude that would not be present in UGS cases, even if we take desirability in this more restricted sense. And indeed, it could require the same mechanisms.

The difference between recognizing that something is desirable for someone else and for ourselves, might then be based simply on a difference in the granularity of the situations involved. Whereas judging that something is desirable for someone else might reduce to the grasp of the general structure of various kinds of situation, judging that something is desirable from our perspective, or from a perspective that we are able to take, involves a much more specific situation, namely, one centred around us. We should return to the question we raised earlier about who "one" and "us" can refer to in this context. Attributions of ability can vary depending on what range of possibilities is taken into consideration. I am now, for example, unable to explain John's odd behaviour, but a version of me who was in a different position could be able to do it. Our attempts at understanding someone often involve either imagining or in fact putting ourselves in a different position. In each case there will be a question of what position one needs to evaluate to make the right judgements. To answer such questions, one needs to grasp the structure of the available candidate positions.

Thus, whereas the grain of the circumstances that we evaluate when something is desirable for us rather than for indeterminate person is potentially much finer, the mechanisms by which we make the relevant judgements are constant. At least in an important range of cases, knowledge of what one may be able to desire, and consequently of desirability in the relevant sense, remains a type of grasp of structure.

This does not mean, however, that the highest form of understanding people can be fully reduced to this self-centered form of UGS, since it could be that the latter has features that exceed what one could get by means of grasp of one's own abilities. There are reasons to think that understanding others cannot be reduced to grasp of desirability in the sense that I have just characterized. One may, for example, come to know that one is able to desire something that one does not actually desire, without understanding how someone else is able to desire it. While one could understand how someone could desire something and take it as a good because one grasps how one could take it as a good, that may not also mean that one would thereby understand how someone in particular (someone who isn't us) could desire something, that is, how it would be desirable for them. This doesn't mean that understanding in the first sense would not contribute to one's overall understanding of others, but the relation between both kinds of understanding is less straightforward than a naive reductive story might lead us to believe.

Furthermore, to say that the former is more valuable than the latter is contentious. Grimm's characterization of UTG makes it out to be like the kind of understanding that we would get by grasping how we could be able to desire something. But if cases like those I just described are plausible, UTG cannot be the highest form of understanding of people either, as Grimm seems to suggest when he says that UTG provides a form of understanding that UGS does not (assuming that by giving us more understanding, it should be valued more). In principle, ideal understanding of others would be simply having the kind of understanding that they would ideally have of themselves, which is the same kind of understanding that we would ideally have of ourselves. While this kind of understanding is something that perhaps is achievable when it comes to understanding ourselves, this is not in general the kind of understanding that we can expect to have of others (although it is 
an open question how pessimistic we should be about the scope of our capacity to do this). The highest form of understanding of others that we may aim for is understanding that includes a grasp of the coherence of their desires towards certain goods, manifests our ability to have desires oriented towards those goods, and approximates their ability to have those desires. In trying to understand others in this sense, we indeed do not reduce ourselves to observing that the structure of the situations explains their actions; we also make the effort to navigate those structures ourselves. This constitutes a thicker sense of grasp of structure: not merely the ability to recognize properties and patterns, but also the ability to exploit that structure for diverse purposes.

\section{Imagined and real desires}

Our previous discussion of the epistemology of desirability suggests that we should treat UTG as described by Grimm as a kind of grasp of structure, or at least as something that essentially involves grasp of structure. This undermines Grimm's distinction. In this section, I want to consider the possibility that there could be ways to obtain knowledge of desirability without going through the process of grasping structure, at least in the ways that I described above.

There is, in fact, a way in which one may find that something is desirable for oneself that cannot be a way to find that something is desirable for someone else, and that, further, does not seem to be a way of grasping structure: finding ourselves desiring it. While desires are sometimes subject to our will, we often simply find ourselves having desires spontaneously (Nagel in The possibility of altruism captures this with his distinction between 'motivated' and 'unmotivated' desires). On a first approximation, it seems plausible that in finding ourselves desiring something, we do not need to grasp the structure of the situation we are in and how it makes it desirable, but we simply find it desirable-because-desired. While judging that something is desirable in so far as we judge that we are able to desire it can be accounted for in terms of mechanisms of grasp of structure, judging that something is desirable in so far as we desire it seems to be a genuinely distinct kind of mechanism of belief formation, a distinct 'cognitive attitude' like the one that Grimm supposes is involved in UTG but not in UGS.

How plausible is it, however, that UTG involves or can involve actual desires that we find ourselves having? Trying to understand how someone could take something as desirable or choiceworthy takes effort, especially when we do not initially take it to be desirable or choiceworthy ourselves. So, one way of thinking about desires in the process of understanding is that, if we come to have them as part of it, such desires are the result of deliberation. One characteristic feature of desires that result from deliberation is that their objects (what we deliberately desire) are the kinds of things that we purposefully adopt as goals on the way to achieve something else, something that motivates them. However, if UTG involves desiring the things that others desire, those desires will not as a rule be something that we will find to be motivated in this way. We don't need to be motivated to act as the individuals that we try to understand. Put simply, we do not need to sustain those desires, and we do not. If desires are involved in UTG, a) they are involved in such a way that they are the result of a deliberate effort, but b) they are not necessarily sustained in the way that deliberate desires normally are.

The need for there to be something that fills those demands can be taken as an argument in favour of the postulation of what has been called imaginative desires, or i-desires for short, sui generis attitudes that are the imaginative analogue of desires. Such i-desires would be somehow "blocked 
off from behavior" (Currie 1997:68), but also be deliberately constructed, perhaps as a form of pretence or simulation. One argument in favour of the postulation of i-desires is that in many cases of strategic thinking simulating someone's beliefs is not sufficient to account for the decisions that they would make. It could happen, for example, that someone believes that in the context of a competitive game there are two alternatives open for their opponent, and that in terms of one's beliefs both alternatives are equally viable courses of actions. To fill the gap, they would have to consider something more than those beliefs. If they have to appeal to desires to do it, they cannot be their own desires either, because they are ex hipothesi not aligned since they are in competition. Such person should simulate their opponents desires as well as their beliefs.

Something like this story has been endorsed by Karsten Stueber for the case of understanding people: "Understanding how another person's considerations can be his reasons for acting (even in the context of a narrative) is then only possible if we use our own practical abilities by reenacting another person's thoughts as reasons and use our own cognitive system in imaginatively recreating his perspective [...] More specifically, we do that by engaging our capacity for reenactive empathy, taking up and simulating his perspective by adjusting our cognitive system in pretending to entertain his beliefs and desires, and quarantining the mental states that we do not share with him" (Stueber 2019:273).

There are difficulties with adopting this strategy for our purposes here. One difficulty is that the construction of i-desires may very presuppose having a grasp of the desirability of the things that are i-desired. Grimm argues that a simulationist strategy is not sufficient for UTG for this reason: "unless I can see or regard particular goals as worth desiring in the first place, mere simulation will still leave an important residue of unintelligibility. I might realize that the person I am simulating is devoted to collecting the saucers of mud and predict his (my?) actions accordingly, but still feel perplexed by the whole project" (Grimm 2016:217).

In our previous example, someone judges that their opponent's goals are worth desiring because they have their own to compare, and consequently know what to simulate. Not all cases are like this, however. One could fail to see what to simulate, precisely because one fails to see that something could be desirable. If this is so, the proposal of i-desires seems to ultimately lead us back to a structural account of our judgements of desirability. Another difficulty has to do with the inferential profile of $i$-desires. The issue is that the $i$-desires model fails to vindicate the inference that something is desirable in the relevant sense from the recognition that something has been $\mathrm{i}$ desired. When we simulate a desire, we take for granted or suppose that what is i-desired is desirable, but for this same reason we cannot infer that it is. If we can i-desire anything at all, we could in principle i-desire anything whatsoever. However, the sense of desirability that is relevant for us is much more discriminating, because something that is desirable in this sense must seem so from a perspective like ours. Some story needs to be given about how i-desires can also be subject to this kind of constraint.

These difficulties suggest that we should adopt an alternative account that does not appeal to the postulation of i-desires (the point isn't that there are no reasons to postulate i-desires, but merely that their postulation is unhelpful for our purposes here). One possibility is to propose the adoption of what we can call an imagination+desire account (in contrast to an imagination+i-desire account like those we described above). Here is a sketch. When we attempt to obtain UTG, we enact various acts of imagination, where we put ourselves (in our imagination) in a position like those subjects we 
want to understand, in a situation where whatever is to be evaluated as desirable is present. In doing so, we come to be in a position to have desires that subjects like them might have. If the position is close enough, our attempts will trigger our capacities to desire in the right way and we will come to have desires catalytically. Note that the thesis is that we can trigger desires catalytically, not, like in Strawson (Mental ballistics or the involuntariness of spontaneity) that all apparent mental activity is just a matter of 'mental ballistics'.

These are not i-desires, but genuine desires. Because they are genuine desires, we can infer that their objects are desirable in the required sense: they are available to us as desirable from a perspective that is fundamentally ours. Furthermore, there is a sense in which we can say that we do not have those desires deliberately but find ourselves having them: they are the side-effect of our putting ourselves in a certain imaginative position. They are not the product of a reasoning process that involves of our grasp of structure, we do not reason 'into' having these desires (admittedly, our deliberate effort to put ourselves in the position to have these desires requires that we grasp the structure of this position -otherwise we would not be able to control our imaginings in the appropriate way- so there is also a sense in which we have those desires deliberately). Because the whole process goes through our imaginings, there is an explanation to why these desires do not motivate us: as Carruthers points out, "real desires will normally lead to real action only when interacting with real beliefs" (2006:99). Since the imaginings that these desires interact with are not real beliefs, they do not motivate us to act like our subjects of study. The view can, then, sort out the issues that give rise to the postulation of $i$-desires in the context of understanding people, and is thus a viable alternative to the imagination+i-desire model. Furthermore, it does involve a kind of attitude that is not, explicitly, a form of grasp of structure.

I suspect that this type of attitude towards the desires of people that we try to understand (desiring what they desire because we imaginatively put ourselves in a position like theirs) is valuable in the ways that Grimm stressed about what he calls UTG: it has a moral value, and it is crucial for our own self-understanding. However, these observations are not sufficient to think that this form of understanding is indispensable or even important in the context of the task of understanding others (and consequently of the social sciences.) One way in which this form of understanding could be valuable for this purpose is that it seems to provide us with a mechanism to recognize and focus on something that gives structure to the action of people (namely, the goods that they desire), in a way that makes them accessible to our perspective (namely, as desirable for us). This is something that one could always demand of our attempts at understanding people. Furthermore, since it takes effort of a special kind that when exercised manifests epistemic virtues, it is epistemically valuable as a kind of epistemically virtuous activity. This suggests a story about epistemic value that is similar to Iris Murdoch's story about moral value, illustrated in her famous example of $\mathrm{M}$ in The sovereignty of good (we want to say that M's change of mind about $D$ is good because her attention to $D$ manifests her sense of justice and love). Likewise, we want to say that taking the effort to put ourselves in a position to desire what others desire is epistemically good because it manifests our overall disposition to pursue the truth, which sometimes thereby succeeds (for a way to understand Murdoch along these lines, see Kieran Setiya Murdoch on the sovereignty of good).

\section{Conclusion}

Let's take stock. We have discussed Grimm's account of understanding in the social sciences, and his distinction between understanding as grasp of structure (UGS) and understanding-as-taking-to- 
be-good (UTG), and how it promises to bridge between humanism and naturalism. In this paper, my goal was to critique, clarify, and extend Grimm's account. I have argued that UTG in Grimm's sense in many cases appears to involve, and indeed require, a form of UGS (the grasp of the structure of the situation that makes something desirable for someone). This is true both of third-person judgements about what may be desirable for others, and for first-person judgements about what one may find desirable. I have argued that ideal understanding should perhaps be conceived in a way that does not just reduce to a way for us to be able to evaluate the desirability of goods, but that also approximates the perspective of others and the way that they must find them desirable. Grimm is right when he says that grasping the desirability of something from our perspective is no mere heuristic for understanding others, but it also isn't the top of the ladder of understanding. Rather, it might be the indispensable means by which we try to approximate it. Finally, I discussed one potential dis-analogy between third-person and first-person approaches: that we may find something as desirable by finding ourselves desiring it. In understanding people, we imagine how they are motivated to act in the ways they do. One way in which understanding of people could escape the model of grasp of structure would be that in this process we in effect do find ourselves desiring what motivates the actions of those we aim to understand. I have suggested that this, if in fact occurs, is valuable.

\section{Bibliography}

Carruthers, P. (2006). Why pretend. In: S. Nichols. The architecture of the imagination, pp. 89-109. Oxford University Press.

Currie, G. (1997). The paradox of caring: fiction and the philosophy of mind. In: M. Hjort; S. Laver. Emotion and the arts, pp. 63-77. Oxford University Press.

Grimm, S. (2016). How understanding people differs from understanding the natural world. Philosophical Issues, 26(1), 209-225. https://doi.org/10.1111/phis.12068

Received 29 Sep 2021

Accepted 30 Nov 2021 